\title{
MIRANDO LA ANTIGÜEDAD GRECORROMANA: PARA PENSAR, CON ARENDT, EL SENTIDO DE PRAXIS Y LEXIS
}

\author{
María Fátima Lobo \\ Universidad del Norte Santo Tomás de Aquino \\ mfatima16@hotmail.com
}

\begin{abstract}
Este trabajo versa sobre la teoría de la acción de Hannah Arendt tal como la encontramos en La condición Humana, obra de1958. En ella Arendt busca recuperar la identidad y el sentido de la acción humana (praxis) como actividad del hombre qua hombre y como materia prima de la política. Para ello, recurre a dos experiencias fundamentales de la cultura política occidental: la polis griega y la res publica romana. El resultado es una teoría de la acción que se ha considerado una gran contribución al pensamiento ético político contemporáneo.

Nos proponemos focalizar nuestra reflexión en dos aspectos de la acción humana históricamente olvidados o confundidos y que Arendt logra recuperar: la acción como revelación y como enérgeia.
\end{abstract}

\author{
acción (praxis) / discurso (lexis) / espacio público /
} revelación / enérgeia

\section{A LOOK TO GRECO ROMAN ANTIQUITY: TO THINK THE MEANING OF PRAXIS AND LEXIS, WITH ARENDT}

This paper is about Hannah Arendt's theory of action, as it is found in La condición Humana (The Human condition), a work from 1958. There, Arendt tries to recover the identity and meaning of the human action (praxis) as man's activity qua man and as raw material of politics. In order to do it, she resorts to two fundamental experiences of western political culture: the Greek polis and the Roman res publica. The result is a theory of the action, which has been considered a great contribution to contemporary ethical political thought.

We propose to focus our reflection on two historically forgotten aspects of human action, which Arendt manages to recover: the action as revelation and as enérgeia.

action (praxis) / discourse (lexis) / public space / revelation, enérgeia 
“(...) el íntimo significado del acto actuado y de la palabra pronunciada es independiente de la victoria y de la derrota $y$ debe permanecer intocado, por cualquier resultado final, por sus consecuencias para lo mejor o lo peor". 1

E n 1958, siete años después de la aparición de Los orígenes del totalitarismo (1951), Arendt nos ofrecía La condición humana. A contrapelo de la creciente y generalizada falta de reflexión de nuestro tiempo, Arendt se/nos propone pensar en lo que hacemos.

Nuestra autora parte de la clásica distinción entre el modo de vida propio del hombre común, hombre de acción (vita activa), y el modo de vida de los pocos que, retirados del mundo, se entregan a la contemplación de las verdades eternas (vita contemplativa). Según esta interpretación, en la actividad del pensamiento que renuncia a los intereses y afanes de la vita activa, los hombres se asemejan a los dioses, se ocupan de realidades imperecederas, se topan con lo eterno; y la condición fundamental de este modo de vida es la quietud (scholia), la liberación de toda actividad que no sea la del noûs. Arendt no discute esa distinción pero advierte que ella se origina en la perspectiva de la vida contemplativa. Su punto de partida es la proclamada superioridad de la quietud que caracteriza la vida del pensamiento, comparada con la cual toda la vita activa fue asumida a partir de un único rasgo interpretado sólo en sentido privativo: su ausencia de quietud (a-scholia). La tendencia fue entonces pasar por alto las distinciones realmente existentes en el interior de la vita activa y, en consecuencia, la dignidad de la acción humana -siempre ligada al discurso (praxis y lexis)-, quedó inadvertida, confundida ya con la labor ya con el trabajo.

La condición humana se nos presenta como el intento arendtiano por adentrarse en la vita activa a fin de recuperar la identidad y el sentido de la acción como actividad del hombre qua hombre y como materia prima de la política. Para ello, Arendt recurre insistentemente a dos experiencias fundamentales y fundacionales de la cultura política occidental: la antigua polis griega y la res publica romana. El resultado es una teoría de la acción que se ha considerado como una de las mayores contribuciones al pensamiento ético político contemporáneo.

En este trabajo quisiéramos focalizar nuestra reflexión en dos aspectos de la acción humana históricamente olvidados o confundidos y que esta concepción logra recuperar: la acción como revelación y como enérgeia.

Algunos críticos han señalado la apabullante preponderancia de las fuentes griegas para la construcción de esta concepción. Nosotros qui-

1 AREndt (1958: 228). 
siéramos señalar también la presencia, fundamental en las meditaciones arendtianas, de la experiencia política romana, uno de cuyos más frecuentados autores, además de Virgilio, es Marco Tulio Cicerón. Las fuentes ciceronianas ayudaron a Arendt a recuperar un concepto de lo público olvidado y resignado por la Modernidad. En él el espacio público, no obstante su carácter contingente, aparece como el más adecuado escenario para la manifestación de la humanitas del hombre, manifestación que acontece públicamente en la articulación de praxis y lexis y ante la presencia testimonial de los pares. ${ }^{2}$

\section{La acción como revelación}

Vivir como ser distinto y único entre iguales. ${ }^{3}$

La humana es una existencia altamente condicionada. Dos condicionamientos operan aquí como presupuestos de la acción humana: mundo y pluralidad. Respecto del mundo, ese gran artificio humano, la casa del hombre, Arendt señala insistentemente su naturaleza fenoménica: en él ser y aparecer coinciden ${ }^{4}$; y los hombres, cuya existencia se inicia con el nacimiento y termina con la muerte, son seres mundanos: para ellos nacer es irrumpir en el mundo apareciendo y morir es abandonar el mundo, desaparecer de él.

Esta coincidencia entre ser y apariencia tiene para Arendt dimensión propiamente ontológica ${ }^{5}$, por tanto, 'lo que aparece' (Erscheinung) no debe identificarse ni confundirse con 'lo aparente' (Schein) que, tal como se entendió tradicionalmente, sería algo superficial que oculta la verdadera realidad, la cual se interpretó, a su vez, como invisible y de un orden superior, no fenoménico. Para nuestra autora la única realidad que conoce-

2 En tal sentido, este trabajo coincide con aquellos intérpretes que reconocen, en la concepción política de Hannah Arendt, la presencia operativa de fuentes que no son griegas y a la luz de cuyos aportes, Arendt logra objetivar las limitaciones del modelo heleno. Piénsese en las fuentes judeocristianas y en las que registran la experiencia política romana. En esta línea localizamos a Jacques Taminieux, Margareth Canovan, Françoise Collin, Julia Kristeva, Fina Birulés, Fernando Bárcena, entre otros.

3 ARENDT (1958: 202).

4 Arendt (1978: 43).

5 Coincidimos con la opinión de RoBerto EsPósito (2000: 119) según la cual, con la afirmación de la naturaleza fenoménica de la realidad "Arendt no reduce el aparece a un horizonte puramente fenomenológico, sino que lo extiende a una dimensión propiamente ontológica" ya que "lo que < aparece> (Erscheinung) a lo que Arendt se refiere, de hecho no es identificable con lo <aparente> (Schein), entendido como algo diferente en la realidad, desde el momento que < ser y apariencia coinciden $>$ ". 
mos y en la que vivimos es de naturaleza fenoménica, pluralmente habitada y contemplada.

Por su parte la pluralidad, otra condición esencial de la existencia humana, es definida como "la paradójica igualdad de los seres únicos"6, el hecho por el cual todos somos igualmente humanos pero "nadie es igual a cualquier otro que haya vivido, viva o vivirá"7. Esta condición de la pluralidad es la conditio per quam de la acción y del discurso humano pues hemos de vivir como seres únicos y distintos entre iguales, praxis y lexis mediante. De allí este fundamental carácter fenoménico e intersubjetivo del mundo humano, que, advierte Arendt, tan bien comprendieron los romanos al emplear "las expresiones < vivir > y < estar entre los hombres $>$ (inter homines esse) y <morir $>\mathrm{y}<$ cesar de estar entre los hombres $>$ (inter homines esse desinere) como sinónimos"8.

Si unimos ambos condicionamientos -mundanidad y pluralidad,- la verdad que reza "Ser y apariencia coinciden" adquiere un original y activo cumplimiento en la vida de los hombres. También para ellos, ser es aparecer, pero la condición de apariencia -común a todo ente mundano- no es en ellos un factum de cumplimiento inexorable.

Al nacer, los humanos aparecen en el mundo y esta aparición prescinde completamente de su deseo y decisión. Aún así, con el nacimiento entra en el mundo un actor nato, un sujeto único dotado con la capacidad de la acción y del discurso, al igual que todos sus congéneres. Consecuentemente, los hombres no sólo padecen estas condiciones (apariencia, mundanidad, pluralidad), ellos las actúan: a) son activamente mundanos -se manifiestan-, b) son activamente únicos -se diferencian, revelan su singularidad-, c) son activamente plurales -se presentan y cortejan el reconocimiento de sus pares-. Arendt afirma: "Mediante la acción y el discurso, los hombres muestran quiénes son, revelan activamente su única y personal identidad y hacen su aparición en el mundo humano" 9 . De donde se infiere que una vida auténticamente humana no puede prescindir de ellos pues acción y discurso "(...) son los modos en que los seres humanos se presentan unos a otros, no como objetos físicos, sino qua hombres"10.

Observemos aquí que Arendt, en lo que respecta a la noción de sujeto, toma distancia de las interpretaciones sustancialistas: en primer lugar define al sujeto como un quién y no como un qué, luego, afirma la singularidad irreductible del quién así como su constitutiva condición de

\footnotetext{
ARENDT (1958: 200)

ARENDT (1958: 22) .

Ibidem.

ARENDT (1958: 203).

ARENDT (1958: 200).
} 
principiante y, finalmente, señala a este principiante como el protagonista (agente y paciente) de una historia -la suya- que será narrada por otros. En palabras de Roberto Espósito: “(...) la identidad subjetiva no es presupuesta, sino que resulta y es consecuencia de una acción <performativa> del sujeto mismo que la comete" ${ }^{11}$. Por lo mismo, Françoise Collin señala que para Arendt "los humanos son los <quien>, los < alguien>, y el alguien se define esencialmente como fuente de iniciativas y de sentido, que no son reductibles a una definición sustancial"12. En este punto es notable el ascendiente de la llamada Filosofía de la Existencia cuyos representantes mayores, Heidegger y Jaspers, fueron también los más influyentes maestros de Arendt. Ya en 1946 formulaba Arendt una tesis central de esta corriente filosófica en los siguientes términos: "no cabe preguntar por el $<$ qué> del hombre como se pregunta por el qué de una cosa, sino sólo por el < quién> del hombre"13.

Arendt entiende que el acto primordial y específicamente humano consiste en la revelación de la singular identidad del agente. Para ello, se requiere la asociación entre praxis y lexis porque mientras el mayor poder de la acción radica en su capacidad para comenzar algo nuevo (initium), para forjar novedades en el mundo haciendo presente y manifiesto la propia unicidad, el mayor poder del discurso está en su carácter revelador de la identidad del que actúa. En estrecha asociación ambos poderes se potencian, se complementan. En palabras de Arendt:

(...) acción y discurso están tan estrechamente relacionados debido a que el acto primordial y específicamente humano debe contener al mismo tiempo la respuesta a la pregunta planteada a todo recién llegado: ¿Quién eres tú? Este descubrimiento de quién es alguien está implícito tanto en sus palabras como en sus actos. ${ }^{14}$

Con cada recién nacido, una novedad absoluta hace su aparición en el mundo. Arendt, con la categoría 'natalidad', alude a esta decisiva condición de la existencia humana, por la cual, no hay vida humana que no se inicie

11 Cf. Roberto Espósito (2000:119).

12 Cf. Collin Françoise (2000: 90).

13 ARENDT (1946: 220). Años más tarde, en La condición humana nuestra autora distinguió entre condición y naturaleza humana a los efectos de especificar que lo suyo, no es un planteo sobre 'lo que' el hombre es, ya que, siguiendo a pie juntillas el planteo de San Agustín en Las confesiones, la pregunta por la naturaleza del hombre, sólo su hacedor podría contestarla: "si tenemos una naturaleza o esencia, sólo un dios puede conocerla y definirla, y el primer requisito sería que hablara sobre un <quien > como si fuera un <que>". ARENDT (1958: 24, nota 2).

14 ARendt (1958: 202). 
con el nacimiento, es decir, con un acontecimiento que tiene en el recién nacido a su sujeto y protagonista aunque no a su agente, no a su responsable ni a su autor. En consecuencia, desde el punto de vista del mundo alguien único irrumpe en él, desde el punto de vista del nacido, él ha sido puesto en el mundo o, al decir de Heidegger, arrojado en él. Ahora bien, este alguien único -sujeto pasivo de su natal irrupción en el mundo- llega dotado del poder para actuar. Para Arendt "Actuar, en su sentido más general, significa tomar una iniciativa, comenzar (como indica la palabra griega archein, <comenzar >, <conducir > y finalmente <gobernar >), poner algo en movimiento (que es el significado original del agere latino). ${ }^{15}$ Por tanto, mediante el poder para actuar, al recién llegado le es dada la posibilidad de asumir y confirmar con sus actos y palabras aquella primera aparición que, prescindiendo de su deseo y consentimiento, lo puso en el mundo; y esta inserción es, por ello, como un segundo nacimiento. De donde se concluye que es imposible predecir con propiedad cómo será la singular historia del recién llegado o como afectará al mundo común. Dado que son initia de los recién nacidos cabe esperar lo inesperado, lo improbable, lo impredecible. En otras palabras, que el hombre es capaz de acción quiere decir que es libre, que tiene capacidad para trascender lo dado. En este punto Arendt es discípula de San Agustín. En el fragmento $3 \mathrm{~b}$ de ¿Qué es la política?, un texto anterior a La condición humana pero publicado póstumamente, lo formulaba así: "El milagro de la libertad yace en este poder-comenzar [Anfangen-Können] que a su vez estriba en el factum de que todo hombre en cuanto por su nacimiento viene al mundo -que ya estaba antes y continuará después- es él mismo un nuevo comienzo" ${ }^{16}$.

Siendo el hombre un 'ser en el tiempo', su respuesta a la pregunta ¿quién eres tú? no puede ser sino un proceso de revelación extendido en el tiempo interpuesto entre el nacimiento y la muerte. Hablamos de una revelación hecha de actuaciones y palabras, que nunca está completa ni es definitiva mientras su protagonista esté vivo ${ }^{17}$. De allí que la acción en tanto cumplimiento y epifanía de la singular identidad del actor, requiera, necesariamente, la presencia de espectadores capaces y dispuestos a recibir y confirmar el quien del agente.

15 Arendt (1958: 201). Cf. Arendt (2005: 77, Fr. 3b).

16 Arendt (2005: 66, Fr. 3a). En el fragmento 3b, ArEndt (2005: 77) nos hace notar que “(...) sólo nos hemos dado cuenta del extraordinario significado político de esta libertad -que reside en el poder-comenzar- hoy, cuando los totalitarismos, lejos de contentarse con poner fin a la libertad de expresión, han querido también aniquilar fundamentalmente la espontaneidad del hombre en todos los terrenos".

17 Cf. ARENDT (1958: 216). 
Además de exponer la propia mismidad ante nuestros semejantes en la publicidad del mundo compartido, el proceso tiene también un carácter reflexivo, un sentido revelador que vuelve sobre el propio sujeto ya que el actor desconoce y no controla su propia identidad antes de exponerse actuando y hablando. Por eso Arendt nos dice: "Sólo puede ocultarse en completo silencio y perfecta pasividad, pero su revelación casi nunca puede realizarse como fin voluntario, como si uno poseyera y dispusiese de este < quién > de la misma manera que puede hacerlo con sus cualidades"18. En palabras de Cristina Sánchez Muñoz: “(...) la unidad, la coherencia y la identidad del agente no es algo dado, sino que es una realización o logro de la acción misma"19. En tal sentido, la autopresentación o revelación del agente tiene el carácter de un riesgo voluntariamente asumido. El riesgo es grande, pues actuando y hablando los hombres revelan, a los demás y a sí mismos, su novedad irreductible, sin poseer ni disponer de antemano del contenido a revelar y, por tanto, pudiendo controlar sólo un mínimo del proceso; la revelación en curso es también autorrevelación.

\section{Necesidad de un narrador}

Pues nadie puede $<$ ser $>$ sin alguien que mire..$^{20}$

El poder revelador de praxis y lexis nos enfrenta a un límite: la unicidad o identidad (<quién>) de alguien se sustrae a "una expresión verbal inequívoca". Nos resulta imposible < solidificar en palabras > la esencia viva de una persona que, sin embargo, se muestra y en tal medida se hace real, se actualiza, en la fusión de acción y discurso ${ }^{21}$. De allí que la más apropiada forma de expresar discursivamente quién es alguien, sea contando su historia (story), esto es, elaborando un relato que conjugue y dé unidad a las actuaciones y palabras del agente desde su irrupción en el mundo públicamente compartido y hasta su desaparición final. Arendt insiste en que el relato histórico manifiesta un poder de revelación del <héroe> de la historia en cuestión, mucho mayor que el que suele atribuirse a las obras por él producidas, de las que sí cabe llamarlo productor o autor ${ }^{22}$. Y si nos preguntamos en qué radica esta superior capacidad comprensiva

8 ARENDT (1958: 203).

19 Cristina Sánchez Muñoz (2003: 191).

20 Cf. AREndt (2005: 145, II Parte, Documento [022385]).

21 ARENDT (1958: 205).

22 Como señala KRISTEVA (2003: 57) Arendt mostró la esencial vinculación entre acción y narración, como específico de lo humano: "a los ojos de la politóloga sólo la acción como narración y la narración como acción completan la vida en lo que tiene de <específicamente humana>". 
del relato histórico, la más fuerte y fundamental razón dice que la persona es siempre más que sus obras: "(...) el trabajo que pudo haber realizado y dejado tras de sí, sólo nos dice cómo es o era"23, en cambio, "(...) la única buena cualidad de todos los dones realmente grandes es que las personas que los tienen siguen siendo superiores a lo que han hecho (...) porque esta fuente surge de quién son y permanece al margen del verdadero proceso de trabajo, así como independiente de lo que realice"24. Y, esta excedencia de la persona respecto de sus obras encuentra expresión en sus actuaciones y palabras.

La narración biográfica resulta entonces la forma más cabal de decir quién es alguien, pero ella ha de ser elaborada y contada por otro, por un testigo sobreviviente que asuma el rol de historiador. El actor del relato, su protagonista, no puede ser el narrador de su propia historia porque su exposición no está 'precedida por' ni 'responde a' una historia previamente poseída. En tanto actor el hombre es libre, no está determinado por un guión previo al que deba ajustar sus actuaciones. De allí las palabras de Arendt: "Nadie sabe a quién revela cuando uno se descubre a sí mismo en la acción y la palabra"25; el autoconocimiento y la autocomprensión son necesariamente a posteriorísticos e incompletos mientras vivimos. Únicamente con la muerte puede decirse que todas las fichas han sido jugadas. Entonces el que fue protagonista de su propia vida requiere de un narrador que elabore discursivamente su historia y, así, descubra su significado. Uno de los ejemplos más frecuentado por Arendt es el de Homero, el poeta narrador de la guerra de Troya, quien ha permitido a la posteridad saber de Aquiles, de Ulises y de Héctor pues rescató del olvido sus acciones y palabras concediéndoles fama inmortal. Para poder hacer esto, el poeta-historiador, asume la actitud y la posición interior e histórica de un espectador: él contempla, no actúa; no está en el teatro de operaciones sino ubicado a una respetable distancia que le garantice buena perspectiva, amplitud de miras e imparcialidad frente a las actuaciones contempladas. Es decir, las historias son obra del pensamiento y del juicio, no de la acción. Y, precisamente por ello, el narrador puede: $1^{\circ}$ ) acceder comprensivamente a los significados manifiestos en lo actuado por los actores y $2^{\circ}$ ) ponerlos en "sus justos términos" salvando las actuaciones de su natural futilidad, extendiendo la propia condición de espectador a los futuros oyentes/lectores y otorgando a la revelación del agente en sus actos y palabras la unidad y coherencia discursiva de una historia (story): el registro narrativo de una vida singular. Tal como señala nuestra autora, "Se establece de este modo

23 ARENDT (1958: 210).

24 ARENDT (1958: 234)

25 ARENDT (1958: 204). 
una distinción entre lo hecho y lo pensado, y a este objeto del pensamiento sólo puede acceder el <espectador >, aquel que no actúa" (las cursivas son nuestras) ${ }^{26}$. En la Odisea (canto VIII) Arendt señala un pasaje que ejemplifica cómo el historiador, con su narración, logra captar en lo actuado un significado que se escapa al propio actor. Se trata de Ulises, quien ya en la corte de los feacios, mientras espera, escucha al haedo cantar una parte de su propia vida, aquella de su riña con Aquiles, su amigo. Y Ulises, que nunca antes había llorado, rompe a llorar: "Sólo al escuchar la historia llega a ser plenamente consciente de su significado"27.

Claro que una vida singular puede inspirar varios relatos debido, en primer lugar, a que ella se jugó en el mundo común que está habitado por una pluralidad de actores, espectadores y testigos, a cada uno de los cuales corresponde una determinada y particular perspectiva desde la cual observar e interpretar; en segundo lugar, debido a que la revelación del agente, como "(...) los antiguos oráculos que, según Heráclito, <ni revelan ni ocultan con palabras, sino que dan signos manifiestos" 28 , se juega en el plano del significado y, por tanto, es susceptible de nuevas lecturas y reinterpretaciones. Los hechos, una vez muerto el actor, serán siempre los mismos, y ha de respetarse la verdad fáctica. La cuestión es cómo los interpretamos y qué valor les asignamos. Piénsese por ejemplo, en las diversas narraciones sobre una misma vida, construidas en base a los mismos hechos pero con resultados diversos, dado que nos entregan imágenes muchas veces antagónicas del protagonista, o porque nos muestran facetas o enfatizan sentidos, no contemplados en los otros relatos. Finalmente señalemos que, para nuestra autora: "Que toda vida individual entre el nacimiento y la muerte pueda contarse finalmente como una narración con comienzo (story) y fin es la condición prepolítica y prehistórica de la historia (History), la gran narración sin comienzo ni fin" ${ }^{29}$.

Esta posibilidad de dejar huellas imborrables de nuestro efímero paso por el mundo, a través de actuaciones y discursos que pudieran ser apreciados y narrados como grandes, no por su utilidad sino por su virtuosismo y belleza, fue claramente advertida por los griegos como una forma de alcanzar inmortalidad. Con ello fundaron la polis, un espacio público eminentemente político, que habitado de un espíritu agonal invitaba a actuar y a conversar entre iguales que son únicos. Así lo interpreta también Julia Kristeva:

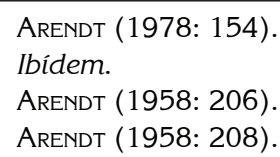


La acción sólo es maravillosa si se vuelve memorable. ¿Dónde reside la memoria? Son los espectadores quienes < completan> hasta su término la historia, y ello gracias al pensamiento ulterior al acto: un completamiento que se realiza por medio del recuerdo, sin el cual, sencillamente, no hay nada que contar. No son los actores sino los espectadores, si tienen la capacidad de pensar y recordar, quienes hacen de la polis una organización creadora de memoria o de historia, de historias, o de una y otras. ${ }^{30}$

Arendt frecuentó aquellas experiencias fundamentales de la Grecia Antigua, no sólo la de las ciudades-estado, también la arcaica de Homero. En ellas rastrea los sentidos originarios de la acción y del discurso y de ellas extrajo finalmente este aspecto esencial del poder revelador de la acción: su carácter agonal. Su modelo primero lo encuentra en la figura de un guerrero, el héroe homérico, Aquiles, de quien se dice que era “(...) el agente de grandes acciones y el orador de grandes palabras" ${ }^{31}$. Digna de fama inmortal, la grandeza de Aquiles, construida a base de praxis y lexis, suponía un gran coraje y se conquistaba en el campo de batalla, en beligerante pugna con los pares. Más tarde, en la experiencia de las ciudades-estado, el modelo propuesto no es ya un guerrero sino un ciudadano y el ámbito de competencia no es ya el campo de batalla sino el ágora. El carácter agonal permanece pero ha cambiado: las posibilidades de alcanzar grandeza se asientan sobre todo en el discurso, en la capacidad deliberativa y persuasiva expuestas públicamente ante la competitiva presencia de los pares, ya que “(...) ser político, vivir en una polis, significaba que todo se decía por medio de palabras y de persuasión, y no con la fuerza y la violencia"32.

30 JuLia KRISTEVA (2003: 90).

31 Ilíada, IX, 443. Citado por AREndt (1958: 39).

32 ARENDT (1958: 40). Esta habitual referencia a la antigüedad griega por parte de Arendt, ha conducido a diversas interpretaciones entre los estudiosos del tema, particularmente a los teóricos de la política quienes reconocen en el pensamiento de Arendt la presencia de dos modelos de acción: uno agonal e individualista y otro deliberativo y participativo. La discusión se abre respecto de los momentos y las obras en las que se localizan estos modelos y respecto de cuál de ellos tiene la prioridad en la concepción arendtiana de la política. Respecto de lo primero hay una línea de intérpretes (Noel O'Sullivan, Peter Fuss, Bikhu Parekh) que localizan la presencia del segundo modelo de acción, el deliberativo y participativo, en obras posteriores a La condición humana, especialmente en Sobre la revolución, o en Desobediencia civil. A su juicio, La condición humana está imbuida del modelo agonal e individualista, y hay quienes la consideran, incluso, una expresión de la grecomanía de Arendt. En interesante discusión con ésta, encontramos otra línea interpretativa que dando muestra de una lectura mucho más atenta y minuciosa de La condición humana, releva en ella la presencia de los dos modelos de acción antes mencionados, así como la presencia operativa de fuentes que no son griegas y, a la luz de 


\section{La acción como enérgeia}

\section{La grandeza específica de cada acto, (...) la propia realización. ${ }^{33}$}

Existe una diferencia fundamental entre acción (praxis) y trabajo (póiesis) que Arendt se esfuerza en mostrar. Mediante el trabajo de sus manos, los hombres, una vez adquirido el saber teórico y el dominio práctico requerido (techné), son capaces de producir o fabricar entes artificiales que quedan en el mundo y lo constituyen. Lo así producido adquiere una existencia propia, independiente del proceso de su fabricación e independiente de su hacedor; en otras palabras, la póiesis da lugar a realidades objetivas, tangibles y durables (da comienzo a algo); y estas reificaciones son la prueba patente de que, por el trabajo, los hombres son capaces de producir realidades distintas de sí mismos. En la acción, en cambio, no se produce nada tangible distinto de sí mismo precisamente porque la actividad no es un medio para la prosecución de un fin. Estrictamente hablando, en la acción el sujeto se realiza a sí mismo al manifestar con sus actuaciones y palabras su singularidad. La acción es revelación del agente, es decir: a) el agente es actor del acto, b) es también lo revelado en la acción -su contenido-, y c) esta revelación, aunque pública, tiene también carácter reflexivo: el agente es destinatario del acto. De modo que, la naturaleza de la acción y del discurso no admite ser explicada en términos instrumenta-

cuyos aportes, Arendt logra objetivar y trascender las limitaciones de la concepción griega. Piénsese en la importancia de las fuentes judeocristianas y de la experiencia romana. En esta línea localizamos a Jacques Taminiaux y a Margareth Canovan quienes acentúan los aportes romanos; a Julia Kristeva y Françoise Collin quienes resaltan las fuentes bíblicas y el ascendiente agustiniano, además de Cristina Sánchez Muñoz, Paul Ricouer y Dana Villa, entre otros. Ciertamente hay consenso en señalar a Sobre la revolución como una obra en la que el modelo de acción es ya claramente participativo y deliberativo (aunque a nuestro juicio no excluye lo agonal). En su contexto la figura del héroe es plural y encuentra su mejor expresión en la figura de 'los padres fundadores'. A nuestro entender, este modelo está ya presente en La condición humana (visible toda vez que Arendt resalta los peligros que anidan en las tendencias individualistas del espíritu agonal o, por ejemplo, en el punto referido a la capacidad de hacer y cumplir promesas, fuente posibilitante de pactos y acuerdos y, con ello, de poder). Incluso en "Filosofía y política", texto de 1954, cuatro años antes de La condición humana, Arendt afirmaba que este espíritu agonal "acabaría por llevar a la ruina a los estados griegos porque pactaba aliazas casi imposibles entre ellos y envenenaba con la envidia y el odio mutuos la vida doméstica de los ciudadanos (la envidia era el vicio nacional de la antigua Grecia)" (1954: 26).

No obstante, el modelo participativo y deliberativo encuentra un desarrollo mucho más acabado en aquella obra posterior, a propósito de sus reflexiones sobre lo propio y genuino del 'momento revolucionario'.

33 ARENDT (1958: 228-229). 
les, como subordinada a un propósito exterior a la propia actividad. Por lo mismo, no cabe esperar de la acción producciones objetivas y tangibles, cuya existencia sobreviva a la actuación; más bien, la revelación de la unicidad del sujeto acontecida en la acción, no existe independientemente de la actuación. Por sí misma, es intangible, fugaz e intrínsecamente relacional. Si algo produce la acción, son relaciones e historias. ${ }^{34}$ En ello consiste la específica productividad de la acción. Recuérdese que, al actuar, los hombres interactúan unos con otros más allá de todo propósito material y utilitario. Se trata del goce que proviene de la acción, en tanto ella es la realización de la condición plural de la vida del agente ${ }^{35}$.

El contraste entre la tangibilidad y objetividad del hacer y la intangibilidad e intersubjetividad de la acción y del discurso tiene gran intensidad en La condición humana. A nuestro entender ello se encamina a señalar como rasgo distintivo de la acción: su naturaleza performativa, de donde se deriva tanto la dignidad como la gran labilidad de praxis y lexis. En tal

34 ARENDT (1958: 214).

35 VolPI (2008: 17-18) señala el ascendiente heideggeriano en la concepción arendtiana de la acción, ascendiente reconocido y expresamente agradecido por la propia Arendt en la carta que junto a una copia de la versión alemana de La condición humana envió a Heidegger en octubre de 1960. Al respecto afirma Volpi: "Tras la publicación de los cursos universitarios de Heidegger estamos en condiciones de comprender las razones de tanta gratitud. (...) Justamente el joven Heidegger es quien había mostrado en sus lecciones que el carácter originario de la vida humana es el actuar, la praxis, comprendida en el sentido aristotélico de <acción>, diferente de la < producción> y de la <teoría >. Había mostrado cómo el privilegio otorgado tradicionalmente a la teoría y el correlativo primado de la presencia habrían hecho de la praxis humana un objeto ante los ojos, una cosa entre las cosas". En esta línea abierta por su maestro "Arendt procura deconstruir el <teoreticismo> del pensamiento político tradicional que apresa el carácter abierto y móvil de la acción en la fijeza de esquemas y categorías que le son heterogéneas". El aporte de Arendt, a juicio de Volpi, radica en que, mientras "Heidegger había redescubierto la praxis pero la había encerrado en el horizonte de un rígido solipsismo de la decisión, Arendt retoma esta intuición pero la invierte en una exaltación del carácter intersubjetivo, plural, público, es decir, político del actuar". También JACQues Taminiaux (1992) señala como punto de partida de las reflexiones filosóficas de Arendt, la apropiación heideggeriana de la Ética a Nicómaco. Arendt coincide en que la praxis pone de manifiesto la individualidad del actor y que establece las modalidades de la excelencia y la distinción. En cambio, discrepa con la reapropiación especulativa de Heidegger, en tanto éste interpreta las formulas aristotélicas de la praxis a partir de los esquemas del bios theoretikos, con lo cual lo reconduce <hacia un solipsismo extraño al tratado ético-político del estagirita >. Frente a esta apropiación de su maestro, interpreta Taminiaux, Arendt propone en La condición humana una <reapropiación praxeológica > en la que resalta como rasgos propios de la acción la publicidad, la multiplicidad y la interacción comunicativa. En La fille de Thrace et le penseur professionnel. Arendt et Heidegger, Paris, Ed. Payot, 1992. Nosotros lo hemos seguido en la reseña presentada por SIMONA FORTI (2001: 60-64).

ARgos 38 (2015) ISSN 0325-4194, pp. 52-71 
sentido, Arendt reflexiona con coraje sobre el significado de la contingencia de las acciones y palabras humanas, sobre su fragilidad, ilimitación, impredecibilidad e irrevocabilidad pero, sin dejarse abatir por ello, señala que lo más propio de la acción es "(...) su inherente tendencia a descubrir al agente junto con el acto" en la publicidad del mundo compartido y ante la presencia de nuestros semejantes. Ciertamente la acción y el discurso provocan consecuencias nunca previsibles y controlables y, sin embargo, esas consecuencias no explican ni contienen el auténtico e íntimo sentido de acción y discurso. En ello consiste, precisamente, la esencial distinción de la acción respecto de las otras actividades de la vita activa: "La grandeza, por lo tanto, o el significado específico de cada acto, sólo puede basarse en la propia realización, y no en su motivación ni en su logro"36. Según esta concepción, que Arendt encuentra tan claramente presente en Homero, en Herodoto y en los relatos de Tucídides y cada vez más difusa en las formulaciones filosóficas de la vida política, “(...) el íntimo significado del acto actuado y de la palabra pronunciada es independiente de la victoria y de la derrota y debe permanecer intocado, por cualquier resultado final, por sus consecuencias para lo mejor o lo peor" ${ }^{37}$. De allí la advertencia arendtiana según la cual el antiguo espectador que acudía a los juegos olímpicos, u Homero al narrar las gestas de griegos y troyanos, juzgaban los acontecimientos en sus propios términos, trataban de captar los significados manifiestos en ellos mismos, de contemplar lo sublime y lo bello de las singulares acciones ofrecidas a su juicio. Nada más distante de las filosofías de la historia propias de la modernidad para las cuales el sentido de cada acto deviene de su coincidencia o subsunción a la ley universal del progreso indefinido de la humanidad. En este sentido, Arendt discrepa en general con todas las filosofías de la historia de la modernidad en las que el juicio de los espectadores queda exclusivamente restringido a la subsunción de lo particular y contingente en la universalidad y necesidad del progreso ${ }^{38}$.

Consecuentemente, para Arendt, la acción y el discurso estarían entre aquellas actividades que Aristóteles llamó enérgeia ${ }^{39}$, es decir: 1) no persiguen un fin (son a teleis), 2) no dejan un producto tras sí (no par'autas erga) y 3) su significado radica enteramente en la pura actuación. Este tipo de actividades son un fin en sí mismas, por tanto, se sustraen a la categoría de medios y fines. Son las actividades más perfectas de las que son capa-

36 Arendt (1958: 228-229).

37 ARENDT (1958: 228).

38 ARENDT (1982: 103).

39 Cf. Arendt (1958: 229). 
ces los hombres, aquellas a las que les cabe la total inmanencia del fin ${ }^{40}$. Entonces, las acciones y palabras de los hombres han de juzgarse por su virtuosismo y grandeza, sólo apreciables en la actuación. Por ello afirma Jacques Taminiaux: "en el momento de su realización la acción pertenece a otro orden fenomenal precisamente por las <identidades intangibles de los actores $>$ y porque no se hace sino que se actúa y, por tanto, se padece al mismo tiempo"41. La patencia con que su grandeza y virtuosismo se abre paso y manifiesta en la esfera pública, provoca su propia memoria; serán hechos memorables que los propios hombres rescatarán del olvido y los tornarán imperecederos al narrarlos en una historia.

El supuesto de todo esto es la existencia de luz y espacio público, un ámbito del mundo creado a fuerza de praxis y lexis a fin de posibilitar y acoger la revelación del actor, la presencia testimonial del espectador y la memoria narrativa del historiador. En palabras de Arendt: “(...) la función del ámbito público consiste en iluminar los asuntos de los hombres ofreciendo un espacio a las apariciones donde pueden mostrar en actos y palabras, para bien o para mal, quiénes son y qué pueden hacer" 42 . Se trata de un ámbito de publicidad propuesto para que, en la interacción de actor, espectador e historiador, se despliegue y realice la dignidad y la eminencia de la que es capaz el espíritu humano en su fugaz paso por el mundo.

Precisamente, el deseo de trascender la futilidad que deviene de nuestra mortalidad es descubierto por Arendt como la fuente que no sólo impulsó la creación del espacio público-político del mundo, sino que lo constituyó como el ámbito en el que le es dado a los mortales conquistar inmortalidad a través de actos y palabras dignos de recuerdo público. La polis se yergue así como una organización para la memoria y para la historia.

Nuestra autora encuentra este concepto de espacio público en la experiencia política de la antigua polis griega, experiencia anterior a las primeras formulaciones de la filosofía política occidental ya que con éstas, piensa Arendt, se impuso la excluyente superioridad de la actividad contemplativa del noûs a expensas de la vida activa de los ciudadanos en el ágora. Sin embargo, cuando Arendt focaliza su mirada en la experiencia política de la república romana, encuentra que, mientras en las ciudades-estado griegas la vida del pensamiento exigía exclusividad y, por ende, la más completa

40 En la misma línea, JeROME KoHn (2007: 30) señala: "El rasgo distintivo de la concepción arendtiana de la acción, como algo opuesto a la conducta, es que tiene su propio fin en sí misma. (...) Arendt creía que Maquiavelo compartía su concepción de la acción como la única actividad pura y perfecta de la vida activa y que Jesús, en su <despreocupación>, es decir en su carencia de metas, era el vivo ejemplo de ello".

41 TAminiaux (2001:87). La version inglesa de este artículo lleva por título "Athens and Rome", en The Cambridge Companion to Hannah Arendt, pp. 168-169.

42 AREndt (1968: 10). 
quietud, (un retiro de la luz pública, de la compañía de nuestros pares y de la participación en la acción), en la tradición de los romanos el afán por el otium no puede ser mayor que el amor a la patria ${ }^{43}$. Si para los griegos en la actividad contemplativa (noûs) los hombres emulan a los dioses, para los romanos "No hay nada en lo que la capacidad humana se acerque más a lo divino que en la constitución de nuevas ciudades y en la conservación de las ya constituidas" 4 . Se comprende así la afirmación de Arendt: "los romanos, quizás el pueblo más político que hemos conocido" 45 y se entiende también su recurrencia a aquella experiencia en su esfuerzo por recuperar y restituir dignidad al espacio público, a la política y a la acción y al discurso humano, después de los totalitarismos.

En este proceso de recuperación de sentido de lo público es continua la mediación de las fuentes ciceronianas. Particularmente interesante resulta aquí la referencia a Cicerón presente en la Laudatio ${ }^{46}$ que Arendt dirige a Karl Jaspers en 1957, con motivo de recibir éste el premio de la paz. ${ }^{47}$ Esta brevísima referencia resulta muy significativa, porque en aquella apelación Arendt busca rescatar un concepto antiguo del ámbito público, más apropiado que el moderno, y cuya base empírica es, precisamente, aquella experiencia republicana.

Muy atinadamente Arendt recordaba que, "(...) somos personas modernas [que] nos movemos con desconfianza y torpeza en público"48. Por

$\overline{43}$ Cf. Cicerón, Sobre la República, LI, Edic. Gredos, Madrid, 1984. Arendt se refiere a este pasaje en "Historia e inmortalidad" al referirse a la eminente dignidad que constituye a la esfera pública y política y de la que está privada la vida de la casa y la familia.

44 Cicerón, op. cit., LI, 7,12. Citado por Arendt en La vida del espíritu, Vol. II dedicado a "La voluntad”. Antes, en el vol. I de la misma obra, bajo el título “¿Qué nos hace pensar?”, a fin de mostrar las peculiaridades de la filosofía romana, Arendt nos remite también al L III, 23 donde se afirma que "...una ciudad debe constituirse de manera que resulte eterna" y al L VI, 13, un pasaje del "Sueño de Escipión" donde se afirma: "Pero para que tú, Africano, estés más decidido en la defensa de la república, ten en cuenta: para todos los que hayan conservado la patria, la hayan asistido y aumentado, hay un cierto lugar determinado en el cielo, donde los bienaventurados gozan de la eternidad. Nada hay de lo que se hace en la tierra, que tenga mayor favor acerca de aquel dios sumo que gobierna al mundo entero que las agrupaciones de hombres unidos por el vínculo del derecho, que son las llamadas ciudades. Los que ordenan y conservan éstas salieron de aquí y a este cielo vuelven". Estos tres pasajes del texto ciceroniano muestran con elocuencia la superioridad, más aún, el carácter divino del genio político, mucho más que del filosófico, en la concepción romana.

45 ARENDT (1958:22).

46 ARENDt (1957: 79-78).

47 Se trata del premio otorgado a Jaspers en 1957 por el gremio de libreros alemanes con ocasión de la aparición de su libro La bomba atómica y el futuro de la humanidad.

48 Cf. ARENDT (1957: 80): "Atrapados por nuestros prejuicios modernos, creemos que sólo pertenece a lo público <la obra objetiva > separada de la persona, y que la persona y la 
tanto, a fin de que el elogio público que se le había confiado conservara todo su sentido, señalaba a su auditorio la imprescindible necesidad de sustraerse al supuesto moderno de tal desconfianza. Se refería al “(...) generalizado prejuicio entre personas cultas de que la brillantez de la luz pública hace superficiales y planas todas las cosas, de que sólo la mediocridad se muestra a gusto en ella y de que por tanto el filósofo debe guardar sus distancias de ella"49.

Así, posicionada en aquel concepto antiguo de lo público, siguiendo a Cicerón y celebrando a Jaspers, afirma: “(...) en los elogios (...) la única consideración es la grandeza y dignidad de la persona a que se refieren"; de la persona, que es siempre más que su obra. Y, por tanto, "es el público el que debe juzgar una vida que se ha expuesto a la mirada pública y que se ha puesto a prueba en el ámbito público". ${ }^{50}$ Con ello Arendt señala en dirección a esta concepción del ámbito público, según la cual es éste un espacio del espíritu, un espacio de luz, el más adecuado escenario para la aparición y despliegue de lo que los romanos llamaron la humanitas del hombre. De esta humanitas nos dice Arendt: "(...) nunca se adquiere en soledad, nunca en virtud de dar al público la obra de uno. Sólo la adquiere quien ha <aventurado> su vida y su persona en la publicidad del ámbito público". ${ }^{51}$

Podríamos inferir, entonces, que entrañadas en el ámbito público yacen, hoy escondidas, genuinas posibilidades de realización del ser del hombre, aquellas relacionadas con su 'ser para los demás' y con su capacidad

vida que hay detrás de ella son cuestiones privadas, y que los sentimientos referentes a estas cosas < subjetivas> dejan de ser genuinos y caen en sentimentalismos tan pronto como se exponen a la mirada pública".

49 ARENDT (1957: 81).

50 ARENDT (1957: 79).

51 Ibídem. Posteriormente, en un texto del año 1961 titulado "La crisis de la cultura. Significado político y social", Arendt vuelve a referirse a Cicerón a propósito de la parábola que Diógenes Laercio atribuye a Pitágoras. En ella se habla de los tres tipos de hombres que asisten a los juegos olímpicos: los competidores movidos por el anhelo de gloria y fama, los comerciantes, movidos por el afán de lucro y los espectadores, el público, que sentado en las gradas del estadio permanece libre de toda actividad e interés que no sea la contemplación del espectáculo y la captación de su sentido. Cicerón, piensa Arendt, habría comprendido a cabalidad la significación política presente en la figura de este espectador, metáfora del juicio humano. Su retiro a las gradas del estadio es condición necesaria para preservar su imparcialidad y para conquistar una amplitud de miras tal, capaz de generar la cultura animi de la que nos habla Cicerón y que Arendt define como "una actitud que sabe cómo cuidar, conservar y admirar las cosas del mundo". Esta sería la actitud más propia del verdadero humanista y la de un político movido por el amor mundi. En "La crisis de la cultura, su significado política y social", en Entre el pasado y el futuro. Ocho ejercicios sobre la reflexión política, Barcelona, Península, 1996, p. 238. 
de acción (praxis), la más eminente capacidad dada al hombre para la vida activa, más allá y por encima de la labor y del trabajo. La Modernidad parece haber perdido este sentido. Vale la pena atender, de forma crítica, el señalamiento arendtiano según el cual los romanos pueden ayudarnos a recuperarlo.

\section{A modo de Conclusión}

En el presente trabajo nos propusimos concentrarnos en dos aspectos de la acción humana, generalmente olvidados o resignados en el mundo moderno y que la teoría de la acción de Hannah Arendt logra recuperar gracias a su recurrencia a ciertos momentos fundamentales de la antigüedad grecorromana. Tales aspectos de la acción son: a) su carácter revelador del quién del actor y b) su carácter de enérgeia, actividad que es fin en sí misma. Ambos aspectos nos obligan a distinguir tajantemente acción (praxis) de conducta o de comportamiento humano con lo cual se nos va perfilando en la praxis, más aún si está asociada a la lexis, una eminencia que es prerrogativa suya por encima de las otras actividades de la vita activa, es decir, de la labor y del trabajo.

En tal sentido, presentamos la acción humana como la actividad por la cual hemos de dar realización a la condición esencialmente plural de la existencia humana, este tener que vivir como seres únicos entre iguales, en la realidad fenoménica del mundo común.

En tanto en la acción y en el discurso el agente revela su irreductible singularidad a los otros y a sí mismo, la propia actuación significa para él una actualidad de su ser, una realización de su unicidad a la que, recordemos, no posee previamente y, por tanto, no dispone de ella como para controlar el contenido a descubrir ni los efectos que producirá: el mismo hombre que actúa es el que se realiza en el acto y, por tanto, el destinatario o paciente de la realización. El acto consiste en el mismo actor apareciendo, y el fin o significado del acto es la epifanía de la singularidad del actor. Por otro lado, el agente que se revela en su acto lo hace públicamente, por tanto, es visto y oído por muchos otros a los que probablemente su actuación, directa o indirectamente, afectará y cuyas reacciones volverán sobre él. En tal caso, el agente padecerá dichas reacciones suscitadas por sus propios actos y palabras, cuyos efectos no siempre le es posible predecir, mucho menos controlar o deshacer. Y, sin embargo, el protagonista es siempre responsable de sus actos y de sus palabras. Ambos aspectos, radicalmente considerados, contribuyen al carácter agonal de praxis y lexis.

En el primer caso, el sujeto es agente y paciente en virtud de la inmanencia del fin en praxis y lexis. Se trata del acto considerado en su estructura ontológica. En el segundo, en cambio, se dice que el agente es 
también paciente debido a que sus actuaciones acontecen en el mundo común al que afectan provocando en él reacciones que volverán sobre el sujeto, afectándolo a su vez. De allí, la siguiente afirmación: "Hacer y sufrir son como las dos caras de la misma moneda, y la historia que un actor comienza está formada de sus consecuentes hechos y sufrimientos" 52 . Aquí se trata del acto considerado en un aspecto ético-político.

El primer sentido nos habla de la eminente dignidad de la acción humana, en tanto realización de la singularidad irrepetible del agente y en tanto capacidad para insertarse en el mundo dando inicio a algo nuevo. El segundo, nos remite a su natural contingencia y consecuente fragilidad, por cuanto las actuaciones humanas resultan, en estricto sentido, impredecibles, irreversibles, de efectos muchas veces ilimitados e incontrolables, todo lo cual otorga al ámbito de los asuntos humanos su característica inestabilidad ${ }^{53}$.

A la luz de estas consideraciones el ámbito público de nuestro mundo común, lo que antiguamente se llamó el 'ámbito de los asuntos humanos' se nos resignifica pues vuelve a exhibir ese carácter épico, ${ }^{54}$ muchas veces trágico, siempre inestable y sorprendente en tanto escenario de las gestas y hazañas humanas. En su sentido más auténtico praxis y lexis suponen el riesgo voluntariamente asumido de la exposición de la propia unicidad en la publicidad del mundo común. De ahí también que, hombres, como Jaspers o Cicerón, que han expuesto su vida y su persona a la mirada pública, sean dignos de reconocimiento y de memoria públicos, en virtud del grande riesgo asumido y del valor ejemplar de su libertad radicalmente probada en horas críticas.

Arendt era consciente de que la praxis, así considerada, tendría en el tiempo cada vez más carácter de hazaña, de algo extraordinario ya que las condiciones del mundo moderno desalientan la acción como tal, a la vez que promueven la conducta o el comportamiento humano susceptible de ser medible, controlable, predecible, perfectamente apto para ser sometido a las leyes de la estadística. En palabras de la autora:

En realidad las hazañas cada vez tendrán menos oportunidad de remover la marea del comportamiento, y los acontecimientos perderán cada vez más su significado, es decir, su capacidad para iluminar el tiempo histórico. La uniformidad estadística no es modo alguno un ideal científico

52 ARENDT (1958: 209).

53 Desde el punto de vista del pensamiento filosófico, especialmente después de Sócrates, un ámbito de tal naturaleza sólo pudo inspirar en los filósofos desconfianza y desaprobación.

54 Este es un aspecto del ámbito público muy bien señalado por MARGARETH CANOVAN (2001: 67 ) en su artículo "Terribles verdades: la política, la contingencia y el mal". 
inofensivo, sino el ya no secreto ideal político de una sociedad que, sumergida por entero en la rutina del vivir cotidiano, se halla en paz con la perspectiva científica inherente a su propia existencia. ${ }^{55}$

Así, en un tiempo en el que todo tiende a eliminar la acción espontánea, a reducir la autonomía personal a través de persuasivas estrategias de uniformización, la acción, en el sentido arendtiano, se vuelve más improbable aún pero sigue siendo posible pues permanece como capacidad del hombre qua hombre. Ella hace de cada sujeto humano alguien dotado con el poder de trascender lo dado e iniciar algo nuevo, clausurando antiguas lógicas (lógicas consideradas imperturbables), insertando en la realidad la novedad de lo no previsible y, por tanto, incontrolable. En todo ello el aspecto agonal permanece.

A nuestro entender, estamos ante una teoría de la acción que recupera y pone de manifiesto la eminencia de la acción humana (praxis) -primera instancia en la recuperación de la dignidad de la vida política- sin omitir en nada su contingencia estructural. La libertad sin soberanía del actor, contiene en su capacidad de acción y en el espacio público del mundo común, unas posibilidades únicas de realización de la pluralidad esencialmente humana: este tener que vivir como seres únicos y distintos entre iguales a los que el mundo recibe con la pregunta ¿Quién eres tú? En palabras de nuestra autora, se trata de “(...) la alegría y la gratificación que nacen de estar en la compañía de nuestros iguales, de actuar en conjunto y aparecer en público, de insertarnos en el mundo de palabra y obra, para adquirir y sustentar nuestra identidad personal y para empezar algo nuevo por completo" 56 . La contingencia se descubre así como un modo positivo de ser.

\section{Bibliografía}

Arendt, H. (1957) "Karl Jaspers: una laudatio", en Hombres en tiempos de oscuridad, Barcelona, Gedisa, 2001, pp. 79-88.

Arendt, H. (1958) La condición humana, Buenos áires, Paidós, 2005.

AREndt, H. (1961) "Crisis de la cultura. Significado político y social", en Ocho ejercicios de reflexión política (1961-1968), Barcelona, Península, 1996.

Arendt, H. (1995) ¿Qué es la política?, Buenos Aires, Paidós, 2005.

ARENDT, H (1967) "Verdad y política", en Entre el pasado y el futuro. Ocho ejercicios sobre la reflexión política, Barcelona, Península, 2003.

55 ARENDT (1958: 54).

56 ARENDt (1967: 277). 
Arendt, H. (1978) La vida del espíritu, Buenos Aires, Paidós, 2002.

AREnd, H (1982) Conferencia sobre la filosofía politica de Kant, Buenos Aires, Paidós, 2003.

Canovan, M. (1992) Hannah Arendt: a reinterpretation of her political thought, Cambridge, Cambridge University Press.

Canovan, M. (2001) "Terribles verdades: la política, la contingencia y el mal en Hannah Arendt", en Hannah Arendt, el legado de una mirada, Madrid, Sequitur, pp. 53-70.

Cicerón, Marco Tulio (1984) Sobre la República, Madrid, Gredos.

Espósito, R. (2000) “¿Polis o comunitas?”, en Fina Birulés (Comp.) Hannah Arendt. El orgullo de pensar, Barcelona, Gedisa, pp.117-129.

Collin, F. (2000) "Nacer y tiempo. San Agustín en el pensamiento arendtiano" en Fina BIRulés (Comp.) Hannah Arendt. El orgullo de pensar, Barcelona, Gedisa, pp. 77-96.

Kristeva, J. (2003) El genio femenino 1. Hannah Arendt, Buenos Aires, Paidós.

Koнn, J. (ed.) (2007) Hannah Arendt. Responsabilidad y juicio, Barcelona, Paidós.

Sánchez Muñoz, C. (2003) Hannah Arendt. El espacio de política, Centro de estudios constitucionales y políticos, Madrid.

VolpI, F. (1998) Sobre Heidegger: cinco voces judias, Buenos Aires, Manantial, 2008.

TaminiauX, J. (2000) "Athens and Rome", en The Cambridge Companion to Hannah Arendt, Cambridge University Press, Cambridge, pp. 165-176.

Taminiaux, J. (1992) La fille de Thrace et le penseur professionnel. Arendt et Heidegger, Paris, Ed. Payot.

TaminiauX, J. (2001) “¿Performatividad y grecomanía?”, en AAVV, Hannah Arendt, el legado de una mirada, Madrid, Sequitur, pp. 71-84.

Fecha de recepción: 17-02-2014

Fecha de aceptación: 03-12-2014 